\title{
DETECTION OF ABANDONED MINESHAFTS USING TOWED-ARRAY CAPACITIVE RESISTIVITY AND REAL-TIME KINEMATIC GPS NAVIGATION
}

\author{
O. Kuras', D. Beamish' ${ }^{1}$, P. I. Meldrum', R. D. Ogilvy ${ }^{1}$, K. Strange ${ }^{2}$, M. Waller ${ }^{3}$, \\ G. W. Roberts ${ }^{2}$ and G. M. Williams ${ }^{1}$ \\ 'British Geological Survey, Keyworth, Nottingham NG12 5GG, UK; E-mail: oku@bgs.ac.uk \\ ${ }^{2}$ Institute of Engineering Surveying and Space Geodesy, \\ University of Nottingham, Nottingham NG7 2RD, UK \\ ${ }^{3}$ School of Chemical, Environmental and Mining Engineering, \\ University of Nottingham, Nottingham NG7 2RD, UK
}

\section{INTRODUCTION}

The UK has a long history of mining but it was not until 1875 that the accurate mapping of mine workings and the submission of abandonment plans became a legal requirement. Where mineshafts are indicated on plans, they may be mis-located due to poor or inaccurate surveying. Consequently, the redevelopment of derelict land in the built environment frequently encounters potential geohazards, such as old adits, bell pits and shafts. These mining relics pose a serious risk to health and safety.

This paper demonstrates how the combination of modern geophysical survey techniques with state-of-the-art satellite-based positioning may assist in the detection of such features. Recent advances in these fields offer the possibility of using towed-array resistivity instruments in conjunction with highly accurate (sub-decimetre) real-time kinematic global positioning systems (RTKGPS). Here we describe the use of multi-offset towed-array capacitive resistivity (CR) with GPS navigation for mapping resistivity over a known mineshaft in the historic mining area of Bonsall Leys in Derbyshire, UK.

\section{THE CAPACITIVE RESISTIVITY (CR) TECHNIQUE}

In the context of mineshaft detection; dense areal coverage and high-resolution datasets are clearly required. A continuous surveying technique combined with dynamic data collection is therefore desirable. Towed-array DC resistivity measurements are highly susceptible to motioninduced noise due to variable galvanic contact and reliable resistivity estimates require heavy oversampling and robust statistical processing (Sörensen, 1996). In contrast, the non-galvanic nature of the capacitive resistivity (CR) technique facilitates dynamic resistivity measurements with favourable noise characteristics (Kuras et al., 2001). The use of low-frequency electric currents allows for capacitive coupling between sensors and the ground. Theoretical equivalence with the DC case is achieved in a low induction number mode of operation associated with quasistationary fields. Under such conditions, conventional DC interpretation schemes are applicable (Kuras, 2002).

At low induction numbers, the complex transfer impedance $Z$ for an array of capacitive sensors based on plate-wire arrangements can be described by

$$
Z=\frac{\Delta V}{I}=Z_{0}\left(1-K^{E s} \alpha\right)
$$


where $Z_{0}$ is a constant, $K^{E S}$ is the electrostatic geometric factor and $\alpha$ contains the electrical properties of the subsurface (Grard, 1990). This "electrostatic formalism" yields a phase-sensitive expression for apparent resistivity which can be shown to reduce to the classical DC expression for the in-phase component of the transfer impedance (Tabbagh et al., 1993; Kuras, 2002):

$$
\rho_{a} \approx-\frac{\operatorname{Im} \alpha}{2 \omega \varepsilon_{0}} \approx \frac{\operatorname{Re} U}{I} K^{D C}
$$

It is therefore important to measure the fully complex transfer impedance for an accurate estimate of resistivity. The British Geological Survey has recently developed a prototype CR instrument which can perform such measurements dynamically for use in towed-array surveys (Beamish et al., 2001).

\section{DYNAMIC SURVEYING WITH GPS NAVIGATION}

The BGS CRI (Capacitive Resistivity Imaging) system was used to acquire apparent resistivity data on 5 channels in equatorial dipole-dipole configuration (Fig.1). The dipole length was $1.5 \mathrm{~m}$, with separations ranging from $1.6 \mathrm{~m}$ to $5.4 \mathrm{~m}$. A differential RTKGPS set-up consisting of two single-frequency receivers communicating via a telemetric link (Fig.2) was employed to establish the position of the roving array in real-time (Roberts et al., 2002; Strange et al., 2002). The GPS information was used for two purposes:

1. to provide accurate positions (horizontal accuracy $\approx 2 \mathrm{~cm}$ ) for the apparent resistivity datum points and

2. to provide a visual navigational aid for the vehicle driver so that the ground could be covered in a regular pattern along parallel survey lines (a $1 \mathrm{~m}$ line separation with some $0.5 \mathrm{~m}$ infill was used here).

The CR data acquisition was controlled by the GPS system, which was programmed to trigger an impedance measurement at predefined distances. A sampling interval of $10 \mathrm{~cm}$ was employed. Surveying was carried out in a near-continuous fashion, which meant that an area of more than $1,500 \mathrm{~m}^{2}$ could be covered in approximately 5 hours, providing a dataset with more than 20,000 datum points per dipole separation.

\section{THE BONSALL LEYS MINESHAFT}

Bonsall Leys in Derbyshire (UK) is underlain by Carboniferous Limestone with interbedded basalt at approximately $20 \mathrm{~m}$ below ground level. Mineralisation of the limestone takes the form of vertical sheets or "rakes" perpendicular to the bedding, which contain a variety of minerals including lead sulphide (galena), calcium fluoride (fluorspar), and calcium carbonate (calcite). Mining has taken place since Roman times and numerous vertical shafts still remain from extensive extraction in the $19^{\text {th }}$ Century. Previous spoil heaps on the surface have been levelled and grassed over. The shaft selected for this study is approximately $6 \mathrm{~m}$ deep and rectangular in shape (approx. $1 \mathrm{~m}$ by $0.5 \mathrm{~m}$ ) with natural limestone walls. The top is lined with stone, and narrows to an opening approx. $0.3 \mathrm{~m}$ in diameter, which is easily traversed by the towed array.

Fig. 3 shows an apparent resistivity map for receiver 1 (the shortest separation) as derived from the towed-array CR survey. The resistive signature of the mineshaft is clearly visible near the centre of the map with a maximum apparent resistivity of approximately $180 \Omega \mathrm{m}$. In the mapped area, the near-surface is dominated by lower resistivities (50-100 $\Omega \mathrm{m}$ ) indicating elevated moisture content following prolonged rainfall, but zones of elevated resistivity $(100-150 \Omega \mathrm{m})$ can also be observed, which are likely to be associated with excavated spoil as much of the area 
comprises reworked ground. NW-SE trending features in the bottom half of the map may indicate the orientation of mineral veins (and their associated workings) which is consistent with others in the area (Ford and Rieuwerts, 1970).

\section{CONCLUSIONS}

We have shown that multi-offset towed-array capacitive resistivity (CR) in combination with GPS navigation can be an efficient tool for detecting abandoned mine workings. Rapid data collection, dense coverage and accurate positioning make this survey technique ideal for the nonintrusive detection of such features.

\section{ACKNOWLEDGEMENTS}

This research was funded by the joint NERC/EPSRC Programme "Urban Regeneration and the Environment (URGENT)", Grant GR/M89584. This paper is published with the permission of the Executive Director of the British Geological Survey (NERC).

\section{REFERENCES}

Beamish, D., Meldrum, P.I.; Kuras, O. and Ogilvy, R.D. (2001): A new capacitively coupled resistivity system for the electrical impedance imaging of engineered structures, Proceedings of the 7th meeting of the Environmental and Engineering Geophysical Society - European Section, Birmingham.

Ford, T. and Rieuwerts, J.H. (Editors) (1970): Lead Mining in the Peak District. Peak District Mines Historical Society.

Grard, R. (1990): A quadrupolar array for measuring the complex permittivity of the ground: application to Earth prospection and planetary exploration. Meas. Sci. Technol., 1, pp. 295-301.

Kuras, O. (2002): The capacitive resistivity technique for electrical imaging of the shallow subsurface. Ph.D. Thesis, University of Nottingham.

Kuras, O., Ogilvy, R.D., Beamish, D., Meldrum, P.I. and Nathanail, C.P. (2001): Capacitive resistivity imaging with towed arrays applied to shallow site investigations, Proceedings of the 7th meeting of the Environmental and Engineering Geophysical Society - European Section, Birmingham.

Roberts, G., Strange, K. and Waller, M. (2002): The Detection of Abandoned Mineshafts using GPS and Capacitively Coupled Resistivity Imaging, FIG XXII International Congress, Washington D.C.

Sørensen, K. ( 1996): Pulled Array Continuous Electrical Profiling. First Break, 14(3), pp. 85-90.

Strange, K., Roberts, G. and Waller, M. (2002): The Detection of Abandoned Mineshafts using GPS and Capacitively Coupled Resistivity Imaging, Proc ION-GPS-02, The 15th International Technical Meeting of the Satellite Division of the Institute of Navigation, Portland, USA.

Tabbagh, A., Hesse, A. and Grard, R. (1993): Determination of electrical properties of the ground at shallow depth with an electrostatic quadrupole: field trials on archaeological sites. Geophys. Prosp., 41, pp. 579-597. 


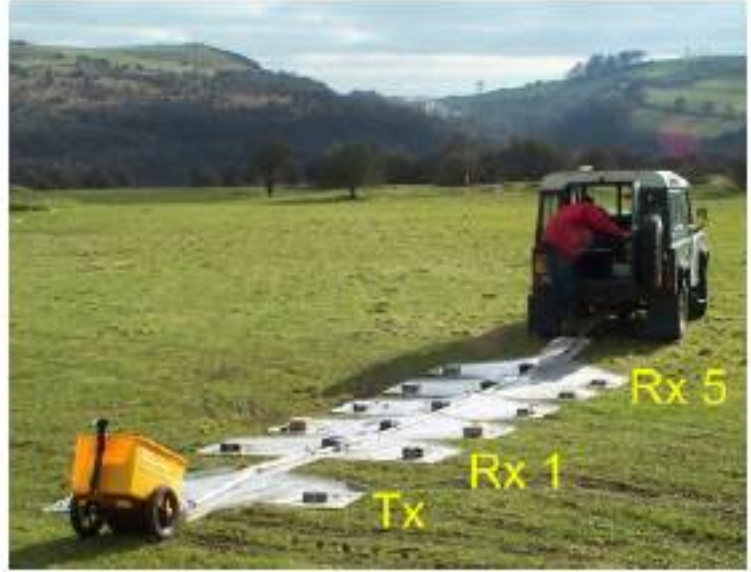

Figure 1: The 5-channel BGS CRI system in field operation at Bonsall Leys.

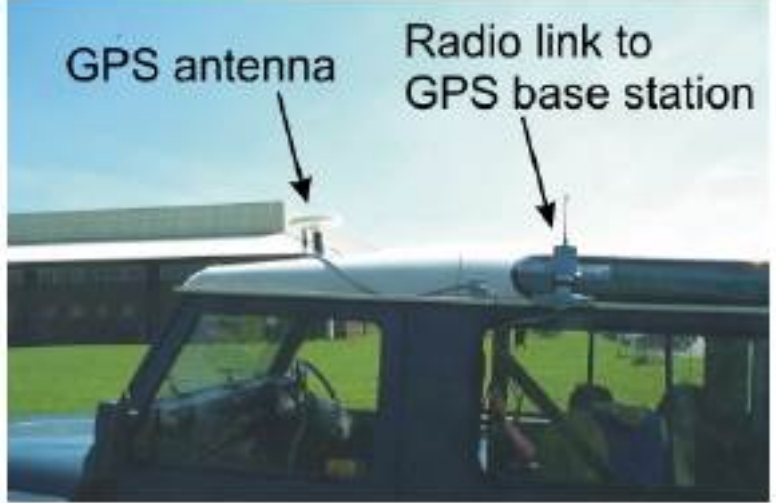

Figure 2: Detail of the GPS antenna and radio modem mounted on the roof of the towing vehicle.

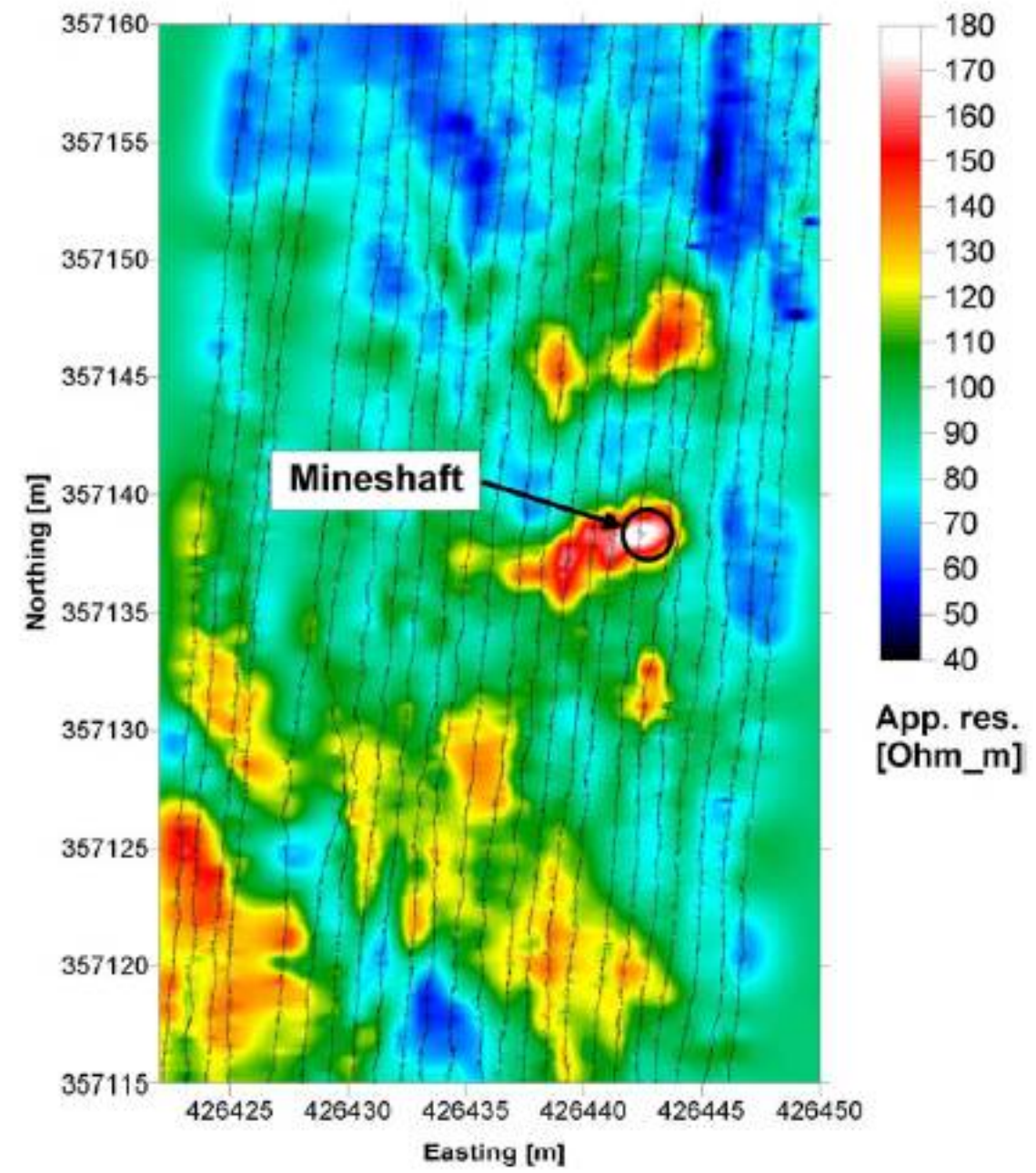

Figure 3: Apparent resistivity map for $R \leq 1$ derived from the towed-array $C R$ survey at Bonsall Leys (dipole length $1.5 \mathrm{~m}$, separation $1.6 \mathrm{~m}$ ). Black lines indicate the towpaths as determined in real-time by GPS.

$9^{\text {th }}$ Meeting of Environmental and Engineering Geophysics, Prague, August 31 - September 4, 2003 Czech Republic 